\title{
The influence of cellular phone "speak" on isiXhosa rules of communication
}

Russell H Kaschula and André Mostert

School of Languages, African Language Studies (isiXhosa), P.O. Box 94, Rhodes University, Grahamstown, South Africa.

Email: r.kaschula@ru.ac.za

\section{Introduction}

Cellular telephones have revolutionised the art of communication across all societies, and South Africa is no exception. Access to this form of communication has made personal contact easier, in both rural and urban contexts. Globally this form of communication has been readily embraced. However, cultural rules that pertain to face-to-face communication are often flouted by cellular phone users. This flouting holds true no doubt across many cultures, languages and contexts. Bloomer (2005:97-100) assesses this flouting of cultural maxims in relation to Grice's cooperative principle. This article attempts to assess how general rules of politeness in isiXhosa have been and are being transformed by what could be termed the "economics of speaking".

In order to establish a suitable paradigm for analysis of any flouting it is necessary to outline the general theory associated with conversational analysis. This article uses the work of Grice (1975) and the maxims of communication which make up Grice's cooperative principle, which tend to differ across cultures, to act as a reference for assessing isiXhosa cellular phone usage. Furthermore, it will attempt to show how the rules now tend to favour a more 
transactional (Sofainou 1989) communicative stance in terms of pay-as-you-go (PAYG) ${ }^{1}$ cellular phone communication, especially in terms of Grice's (1975:49) cooperative principle.

In regard to this principle, Brown and Levinson (1987:82) maintain that a "socially neutral presumptive framework for communication" emanates from Grice's maxims and that politeness theory may be a better barometer of cooperation in the first instance. However, cellular phone communication indicates that there is nothing presumptive or neutral when applying Grice's framework to such a communicative context. The PAYG communicative environment is impacting on general rules of politeness and spawning new communicative rules for effective communication. These new rules conflict with traditional notions of ubuntu and the type of information which is generally associated with culturally acceptable communication skills in isiXhosa. Discourse and conversational analysis theory offers suitable platforms that can be applied to cellular phone "speak" in order to evaluate the contention of this rule transformation.

\section{Discourse and conversational analysis}

Discourse analysis refers mainly to the linguistic analysis of naturally occurring connected spoken and written discourse: "discourse analysis is concerned with language in use in social contexts, and in particular with interaction or dialogue between speakers" (Stubbs 1983:1). This definition indicates that discourse analysis is ideally suited to analysing communication between people using cellular phones, in this case isiXhosa speakers specifically. Similarly to Stubbs (1983:1), Brown \& Yule (1983:1-26) state that the analysis of discourse is the "analysis of language in use" and that "the discourse analyst treats data as the record (text) of a dynamic process in which language was used as an instrument of communication in a context by a speaker/writer to express meaning and achieve intentions".

Although language is embedded in culture, and vice versa, it is through verbal interaction that any large-scale relationships between language and society are realised. Stubbs (1983:7) observes that:

...sociolinguists will have to incorporate analysis of how conversation works: that is, how talk between people is organized: what makes it coherent and understandable, 
how people introduce and change topics: how they interrupt, ask questions, and give or evade answers: and, in general, how the conversational flow is maintained or disrupted.

Developing an understanding of cellular phone speak in terms of Stubbs's definition, will reveal much about the relationship between individuals. It will also allow one to assess the changes in rules of politeness and social etiquette as acted out in this form of verbal communication.

To achieve this parts of cellular phone communication are analysed to identify the regularity of concepts such as turn-taking, openings and closings, adjacency pairs and Grice's cooperative principle. In order to analyse the cellular phone conversations below and to assess how conversational analysis applies to these conversations, it is important to take into account the context of the conversation as well as the "social distance" between interlocutors (Dlali 2003:131-143).

The researcher applied two methods when recording conversations: Firstly, the researcher recorded their own cellular phone conversations, with associated permission to use the conversation in research obtained from the second participants once the conversation was concluded. Secondly, the conversations of others were recorded and the participant whose voice was recorded was asked to fill in the utterances of the second interlocutor, with the necessary agreements.

The researcher also observed body language wherever possible and conducted interviews using questionnaires which were completed by fifty research subjects, with an even split between younger and older research subjects. Selected extracts from the material have been included to offer evidence for the argument in question and assess the degree to which rule changes are present. While the sample size is relatively small, the prima facie evidence offers sufficient anecdotal support for the premise. 


\section{Grice's maxims and conversational isiXhosa}

According to Richards \& Schmidt (1983:116), conversation involves "an ongoing, developing and related succession of utterances". There are rules of cooperation between interlocutors that apply to such "utterances". The co-operative principle was developed by Grice (1975:49), and within this principle four maxims are identified. These maxims reflect cooperative behaviour which speakers observe in effective conversation. Richards \& Schmidt (1983:120) set these out as follows:

(i) Maxim of quantity: Make your contribution just as informative as is required. Do not make your contribution more informative than is required.

(ii) Maxim of quality: Make your contribution one that is true. Do not say what you believe to be false. Do not utter that for which you have little or no evidence, i.e. where evidence is lacking.

(iii) Maxim of relation: Make your contribution relevant.

(iv) Maxim of manner: Avoid obscurity and ambiguity. Be brief and orderly. Avoid unnecessary prolixity.

In terms of isiXhosa these maxims generally apply as follows: the maxim of quantity is flouted in that more information is given than is required in conversations (Kaschula 1989:103). This is particularly true of greetings where participants provide information at a measured pace and where information which does not concern the immediate participants is sought and given, for example, enquiries about the general health of family members who are not privy to the conversation. This also affects the maxims of relation and manner. Information which may not be relevant to the immediate participants in a conversation may be given and it may not necessarily be brief and to the point.

The use of these maxims and their application across cultures may vary. The maxims of quantity, relation and manner may well differ in isiXhosa and English, especially when related to face-to-face communication. However, with the impact of cellular communication, there is prima facie evidence that these rules have changed and do not apply when using this form of communication. This is explored in relation to the conversations analysed below. 
These cross-cultural differences are further explored by Dlali (2003:131-143) when he analyses how isiXhosa speakers, for example, manipulate the social factors involved in the assessment of the seriousness of a face threatening act. This relates to the "social distance between the participants, the relative power of the participants and the ranking of the imposition of a given act". Dlali (2003:131) contends further that "responding to a complaint is also an important factor as it promotes further interaction." However, insofar as cellular phone communication is concerned the response is often not in line with what may be required to stimulate further interaction. In fact the opposite may prevail in terms of which either of the speakers wishes to terminate the conversation, and initial research indicates this is usually the initiator of the call.

Face-to-face spoken isiXhosa requires a certain type of conversational ability owing to rich cultural traditional and social norms. This is considered of great communicative significance, hence rules of diplomacy which result in giving more information than is required in terms of Grice's maxims (Kaschula 1989:103). This does not generally encourage adherence to the maxim of manner, in other words, being brief and orderly. It is in fact this very point that is emphasised in isiXhosa cellular phone speak, contrary to the rules that pertain in face-to-face communication. Speakers may therefore appear rude and impolite. This aspect, related to quantity and manner, seems to have been directly imported from English into isiXhosa cellular phone speak. The following exchanges or adjacency pairs (which are characteristic of this particular conversation) support this point of view. This conversation took place between the researcher $(\mathrm{R})$ and an elderly male Xhosa speaking author from the village of Bedford in the Eastern Cape, Mr Calana (C).

C: Unjani Njingalwazi - usandikhumbula?

R: Ndithetha nabani?

C: Uthetha noTat' uCalana

$R:$ Ooh - ndiyakukhumbula tata, usaphila?

C: Uyibonile incwadi yam?

$R$ : Ewe ndikhe ndayifunda. Ndiyinikwe nguRobert.

C: Ucinga ntoni ngayo? Ndingakuzisela iikopi? Ndineekopi eziyi-500.

R: Ndinayo ikopi, kodwa mhlawumbi singayisebenzisa kunyaka wokuqala.

C: Ndizizise nini ke? Ndingazizisa kule veki? 


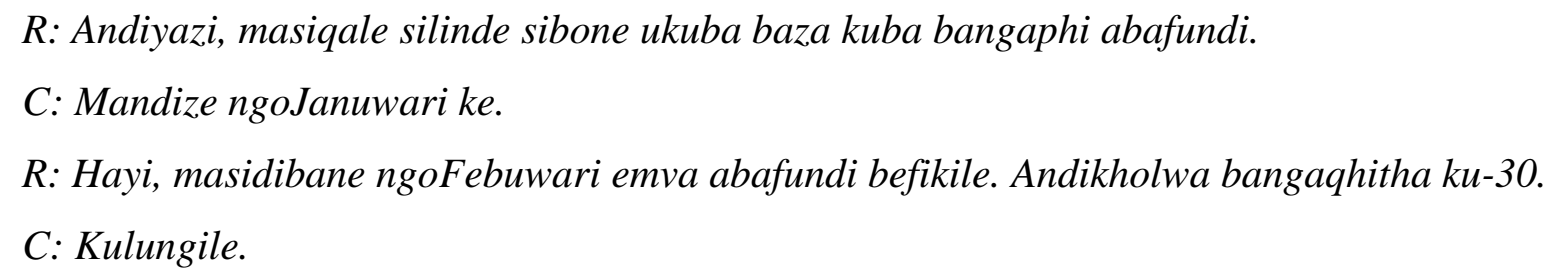

C: How are you professor - do you still remember me?

R: With whom am I speaking?

C: You are speaking with grandfather Calana.

R: Oh, I remember you, grandfather. Are you still well?

C: Have you seen my book?

$\mathrm{R}$ : Yes, I have read it. Robert gave it to me.

$\mathrm{C}$ : What do you think of it? Can I bring you copies? I have 500 copies.

R: I have a copy, but maybe we can use it in the first year.

$\mathrm{C}$ : When can I bring them then? Can I bring them this week?

R: I don't know, let's first wait and see how many students there will be.

C: Let me come in January then.

R: No, let's get together in February once the students arrive. I don't think they would exceed thirty in number.

C: Okay.

The economic nature of the conversation is clear as the author attempts to secure orders for his book. Applying Grice's maxims offers some interesting insights into the exchange above. The author does not respond to a request for greetings and simply moves on to advertise his books. Likewise, as soon as the details of how many books would be required are alluded to, the conversation is concluded abruptly without any appropriate concluding remarks. Even though this conversation is between an elderly man and a younger male, the rules of politeness are clearly flouted, especially in terms of the greeting procedure. However, the conversation is of a "transactional" nature rather than being "interactional" in nature (Sifianou 1989:527), and the associated costs of the PAYG call need to be acknowledged and taken into account.

Conversation should be viewed as a form of interaction rather than just a sequence of utterances. Therefore, the speech acts that occur may be influenced by the type of activity or 
speech event, as well as the situation in which it takes place. This is true of cellular phone speak where the situation creates a less personal and more detached manner of speaking as seen above, which in turn affects the sequence of utterances and consequently may have implications for the application of Grice's principles.

Grice's work has been criticised as anglocentric (e.g. Clyne 1987, 1994; Bowe \& Martin 2007). However, insofar as cellular phone communication is concerned it does seem that a more Eurocentric set of rules apply as opposed to standard rules of ubuntu and isiXhosa politeness. This offers scope for assessing the nature of technology and its dictates in terms of communicative etiquette, which is beyond the scope of this article.

Brown \& Levinson (1983:127) are of the opinion that social interaction, cultural norms and environmental factors all need to be taken into account when interpreting conversation. It is, however, recognised by Grice (1975:49) that sometimes people fail to observe the maxims by flouting, violating or opting out of a maxim. More importantly, Clyne (1994:194-195) has suggested certain revisions be made to Grice's maxims. Clyne states that in the case of quantity and the notion of information these should be considered "within the bounds of the discourse parameters of the given culture." Clyne further suggests that with regard to quality, the notion of truth should take place "within your own cultural norms." In terms of manner and the notion of avoiding obscurity, this should occur "unless this is against the interests of politeness or of maintaining a dignity-driven cultural core value, such as harmony, charity and respect." In other words, the discourse should be structured according to the "discourse parameters of your culture."

Clyne's revisions further reinforce the point that isiXhosa cellular phone conversations are in fact a violation of culture-specific rules of politeness as witnessed in the conversation between Mr Calana and the researcher. According to Bowe \& Martin (2007:14) "notwithstanding the above criticism and revisions, Grice's approach has served as a basis for research in the area of pragmatics and, in its various adapted forms, has been the basic theoretical framework for much of the studies into intercultural communication."

Conversations are engaged for a plethora of reasons, from exchanging information, maintaining a friendship, and negotiating statuses and roles to establishing new relationships 
and roles. Each conversation offers an opportunity to be analysed in terms of interactional acts. According to Richards \& Schmidt (1983:126), rather than considering a conversation as a sequence of speech acts it would be more accurate to consider conversation as a "matrix of utterances and actions bound together by a web of understandings and reactions."

Conversations are not necessarily based on speech acts such as requests and assertions, but rather interactional acts such as challenges, defences and retreats. These are determined by the status of participants in the conversation, their rights and obligations and other interactional factors. The application of Grice's maxims and cooperative principles are likely to be dependent on these aspects.

Consider the following utterances: Andina-airtime, khawundifowunele back 'I don't have airtime, please phone me back'. Alternatively, 'siza kuphinda sithethe, ibhetri yam iphelile 'we will talk again, my battery is finished', with the latter being of a more face-saving nature in the sense that the interlocutor does not blatantly state that they have no money or air-time. The emerging phenomenon of sending "Please Call Me" text messages, again flouts rules of politeness and the expectation is then blatantly transferred to the recipient who has to choose whether or not to initiate a conversation, at their own expense. Across cultures this can be considered an invasion of privacy where Grice's maxims are transferred to the recipient of this text message even before the conversation begins. ${ }^{2}$

\section{4. "Economics of speaking" and rule flouting}

For an interaction to qualify as a conversation, it is necessary for an exchange to have occurred "in which an initiation (I) by A is followed obligatory by a response (R) from B, and optionally by further utterances. The minimal structure is therefore (IR)" Stubbs (1983:131). Consequently, the predominant analytic framework for assessing and contextualising conversation is then the pair (IR), as seen in the previous example of a recorded conversation. Conversational meaning is communicated and interpreted through the use of ordered and related adjacency pairs.

Coulthard (1977:70) expands on this notion by stating that "[a]djacency pairs are the basic structural units in conversation." These include a summons and answer, two farewells, or a 
question and answer. The existence of a pair is central to the concept of turn-taking in any conversation; a pair also enables the selection of the next speaker and the avoidance of any overlap or gap in the conversation. Where the first pair is not answered as would be expected due to some misunderstanding, a side-sequence may well occur. This does not necessarily conform to the pair sequence requirement; for example, a statement should ordinarily be followed by a continuation or relevant comment. In the case of miscommunication this is followed by a side sequence, as in the conversation analysed above where the author miscommunicates regarding the sale of his books and the following side sequence occurs:

STATEMENT:

Andiyazi, masiqale silinde... 'I don't know, let's first wait...'

SIDE SEQUENCE

MISAPPREHENSION: $\quad$ Mandize ngoJanuwari ke. 'Let me come in January then.'

CLARIFICATION: Hayi, masidibane ngoFebuwari emva abafundi befikile... 'No, let's meet in February once the students have returned...'

TERMINATOR: Kulungile. 'Okay'.

Further scholarly developments with regard to conversational analysis have been made by Sacks, Schegloff \& Jefferson (1974). Their findings involve the study of topics related to conversation which include the cooperative principle, speech act and interactional act, adjacency pairs, openings and closings, turn-taking, repairs and topic choice. The concept of an 'adjacency pair' is also referred to by Stubbs (1983:7) more broadly as an "exchange". Richards \& Schmidt (1983:128) conclude that "the basic rule of adjacency pair operation is that when a speaker produces a recognizable first pair part that the speaker should stop talking and the conversational partner should produce a recognizable second pair part. Adjacency pairs thus provide for turn-taking, and also prescribe the type of talking that the next talker can do."

With cellular phone communication these adjacency pairs are often ignored, especially if rules of politeness come into play in a situation which requires further elaboration, yet one of the interlocutors sees this as a waste of time in the sense that they do not want to volunteer any further information. Take, for example the following recorded snippet from a cellular phone conversation between two young brothers where issues of "power" and "politeness" are equalised as they are about the same age - twenty-three and twenty-five years old, 
respectively. One of them has recently passed his first year at Rhodes University whilst the other faces exclusion from the University and is planning to appeal against this possible exclusion:

\section{A: Mfondini, uphi?}

B: NdiseBhayi.

A: Wenza ntoni eBhayi? Uyayazi nje ukuba isikolo sivulile. Kufuneka wenze i-appeal.

B: Uyayazi nje ingxaki yam. (End of conversation)
A: Friend, where are you?
B: I am in Port Elizabeth.

A: What are you doing in Port Elizabeth? You know that the university has opened. You have to put in an appeal.

B: You know what my problem is.

Immediately after the conversation the researcher spoke with student A, who said that, he really did not know what was going on with his brother. He requested that the researcher as an authority figure at the University should speak with him and ask him to come in and fill in the appeal form. He noted that he really did not know what to do to convince his brother to try and continue his studies.

This conversation shows that the notion of adjacency pairs can be tampered with as there is always the option of simply ending the call if one of the interlocutors feels threatened in any way, thereby flouting Grice's maxim of quantity. This means that A cannot make use of probing questions in order to illicit information from $\mathrm{B}$, as one would normally do in a conversation. There is always the option of announcing that the air-time has run out or that the battery of the cellular phone is about to lose power. In this instance B simply ended the call, probably due to the equalised power relations between the two interlocutors. This conversation simply resulted in four utterances due to the sensitive nature of the conversation, i.e. the interlocutor's possible exclusion from the University and his lack of willingness to discuss this issue telephonically. The maxim of quantity is once again not fulfilled. While this may not be specific to an isiXhosa exchange, the degree to which it ignores rules associated with face-to-face exchanges is clear. 
According to Bowe \& Martin (2007:4) "[d]ifferent languages have different ways of marking politeness. People from some cultures tend to favour directness, while people from other cultures favour less directness. Even so, directness may also vary in relation to social context." In this instance it is the context of cellular phone communication that seems to favour and encourage directness, which runs contrary to general isiXhosa rules of politeness. Bowe \& Martin (2007:26) state that "[m]any people think of politeness as the use of extremely formal language, but most linguists perceive politeness as a continuum of appropriate communication". It is clear from the examples given that in isiXhosa cellular phone communication that "appropriateness" is not always a consideration in contemporary communication. These examples above support what Brown \& Levinson (1987:24) refer to as "threatening to the face" in the sense that the person who has failed and has been excluded from the University does not feel comfortable talking about their situation. Instead of allowing for a "softening" to take place, the communication is simply ended. Bowe and Martin (2007:28) conclude that "the key observation is that politeness has two important aspects; preserving a person's positive self-image and avoiding imposing on a person's freedom."

\section{Openings and closings: further analysis}

The requirement of adjacency pairs allows for the participation of both parties to a conversation and allows for further communication. However, from the research undertaken there seems sufficient evidence that adjacency pairs in the form of openings in isiXhosa cellular phone communication are no longer structured. They include colloquialisms such as heita! 'hey!'; m'fethu 'friend'; hola 'howzit' and similar unstructured openings. In fact, in some cases openings have represented a play on major advertising campaigns. For example, yello mello, yello summer instead of 'hello' or yebo 'hi', as used in the Vodacom advertisement. The customary enquiry regarding the person's well-being and that of their family's health, in the form of adjacency pairs, which is characteristic of face-to-face isiXhosa conversation no longer forms part of the introductory cellular phone conversational rules of politeness.

Openings can also include phrases such as ungubani 'who are you?' or ndithetha nabani? 'With whom am I speaking?', i.e. if the interlocutor has not identified himself or herself. The 
conversations recorded seem to reflect an assumption that in isiXhosa cellular phone calls, the person who is initiating the call should be immediately and automatically identified by the recipient of the call and should not be required to identify themselves.

Schegloff (1968:351) notes that telephone openings are part of a broader category of a summons-answer sequence. The phone rings which amounts to a summons and the recipient answers with the typical 'hello' molo or the colloquial heita in isiXhosa.

Richards \& Schmidt (1983:134) observe that closing does not just happen "but must be made to occur by coordinated activities of the conversationalists." A speaker's completion must not allow for the other speaker to talk. Once again, the simplest way is to make use of a terminal adjacency pair. Sacks \& Schegloff (1974) argue that closings can be preceded by possible pre-closings such as okay or alright. Such a pre-closing may lead to a terminal exchange. It may also be an indication that a topic is being closed and other topics may then be introduced. It becomes clear in cellular phone conversations that these pre-closings now manifest as closings, thereby amounting to a terminal exchange. Such pre-closings include kulungile 'okay' and phrases such as Siza kuphinda sincokole 'We will chat again.' Even the utterances Sure or Later now amount to a closing rather than a pre-closing. Pre-closings now include phrases such as ndiseteksini, va? 'I'm in the taxi, do you hear?' or uzundibhaze 'you must buzz me', followed by sure or shapu 'sharp' as a closing. Again, from a politeness point of view these curt and short openings and closings could be construed as rude.

\section{Topic choice: further analysis}

In terms of effective conversational analysis it is necessary to elaborate on the notion of 'topic choice'. According to Richards \& Schmidt (1983:136), "[t]he way topics are selected for discussion within a conversation and the strategies speakers make use of to introduce, develop, or change topics within conversations constitutes an important dimension of conversational analysis." The suitability of topics depends on the person that one is speaking to and the circumstances surrounding the conversation. Coulthard (1977:75-76) states that "[s]ome topics are not relevant to particular conversations ... and the sustainability of other topics depends on the person one is talking to." Generally speaking, the nature of isiXhosa cellular phone conversations remains limited in comparison to face-to-face communication, 
resulting in only necessary information being imparted. This has a concomitant influence on topic choice, which becomes regulated by the economics of speaking, or alternatively the "cost of politeness".

In the following recorded conversation the topic-choice, i.e. the placement of a child in a crèche, is clearly pursued. This is one of a series of recorded conversations with this topic choice. The interlocutors are the same age, twenty-six years old. The father of the child has just moved from Grahamstown to Cape Town where he has taken up a position as an articled legal clerk. The father needs to place the child in a crèche in Grahamstown and his friend is assisting him in this process.

\section{A: Bulelani (first name).}

$B$ (father): Nguwe?

A: Thetha, uthini? Ndiyakuva.

B: Jonga ke, yimalini, ndicinga le nto yecreache?

A: Apha yiR450.

B: 450 per month?

A: Ewe per month.

B: Andiyazi this year if I can afford it. I have a little bit of some financial problem. Are you sure, per month?

A: Andikabi sure-sure.

B: What about half-day?

A: Ndicinga yiR350.

B: Phinda ubafowunele. What about transport?

A: I reckon Khustar is your man. Talk to him.

B: Uyamazi laa mntu. He's not reliable... and uyanxila kakhulu to drive for young toddlers.

A: Give him the benefit of the doubt. He is just a human, he can change maybe. Okay. Iza kubaunderstood. Ndiza kutshekisha. Ndizama ukuorganayiza.

B: Okay, alright.

A: Shapu. (End of conversation)
A: Bulelani.
B: Is it you? 
A: Talk, what do you have to say? I can hear you.

B: Look then, how much is it, I am thinking of this thing of the crèche?

A: It's R450 here.

B: R450 per month?

A: Yes, per month.

B: I don't know if this year I can afford it. I have a little bit of some financial problem. Are you sure, per month?

A: I am not sure-sure.

B: What about half-day?

A: I think it is R350.

B: Phone them again. What about transport?

A: I reckon Khustar is your man. Talk to him.

B: You know that person. He's not reliable... and he drinks a lot to drive for young toddlers.

A: Give him the benefit of the doubt. He is just a human, he can change maybe. Okay. It will become clearer. I will check. I am trying to organise.

B: Okay, alright.

A: Shapu. (End of conversation)

What is unusual about the above conversation is the opening by making use of a first name which was loudly shouted out. This may be due to commonality of age and familiarity.

The common recurrent features related to topics are topic nomination, ratification (acceptance), elaboration and comment (by the listener). This is clear from the above where B offers "the crèche" as the topic nomination, followed by elaboration and comment by both interlocutors. The conversation is also largely "transactional" rather than "interactional" due to the economics of speaking as outlined earlier. Take also the following example from the conversation between the researcher and Mr Calana above where this process is clearly followed:

NOMINATION: $\quad$ Uyibonile incwadi yam? 'Did you see my book?'

RATIFICATION: Ewe ndikhe ndayifunda... 'Yes, I have read it...'

ELABORATION: Ucinga ntoni ngayo? Ndingakuzisela iikopi? Ndineekopi eziyi-500. 'What do you think of it? Can I bring you copies? I have 500 copies.' 
COMMENT: $\quad$ Ndinayo ikopi, kodwa mhlawumbi singayisebenzisa kunyaka wokuqala. 'I have a copy, but maybe we could use it with our first years.'

\section{Turn-taking: further analysis}

Turn-taking also offers significant insights in terms of conversational analysis. According to Stubbs (1983:52) "[o]ne of the basic facts of conversation is that the roles of speaker and listener change, and this occurs with remarkably little overlapping speech and remarkably few silences." The distribution of talking between the participants is governed by turn-taking norms and conventions which determine who talks, for how long and when. A basic rule is that one person speaks at a time.

Turn-taking is also affected by rank and age. According to Richards \& Schmidt (1983:141) "assertion of the right to talk is an indicator of the power or status of the speaker and the degree to which the participants in the conversation are of the same or different ranks. Turntaking is one way in which roles and statuses are negotiated in conversation." This is clear from the conversation between the two students concerning re-admission into the University. Their equal status allows the speaker to switch off the phone as they simply do not want to engage with the second interlocutor as they feel interrogated.

Implicit in this interaction is the issue of 'face'. Goffman (1967:13) suggests that rules of politeness need to move away from the individual to the society in a broader sense. This is supported by de Kadt when analysing Zulu society and rules of politeness. De Kadt (1998:188) states that Zulu speakers make use of both verbal and non-verbal means of communication in addressing the issue of 'face'. Greeting rituals are compulsory and are generally performed by the subordinate person in a conversation. Forms of address such as baba kaSipho 'Father of Sipho' and mama kaSipho 'Mother of Sipho' or similar are used to acknowledge seniority and status which are customary in status laden engagements. However, cellular phone speak brings the communication back to the individuals rather than the society, meaning that such rules may no longer necessarily apply. In this regard, Bowe \& Martin (2007:69) cite a Kenyan colleague whom they interviewed where she acknowledged that "greeting rituals in her culture in the form of turn-taking are so elaborate that if you happen to 
see a friend or relative approaching and you are in a hurry, it is better to avoid the person by crossing the road, than to cut short the greetings ritual".

Similarly, within the amaXhosa community, indeed perhaps as an African phenomenon, the emphasis of cellular phone contact is both functional and interactional, and this affects turntaking. The notion of ubuntu lends itself towards interactional conversation. Arguably, however, in terms of the economics of speaking when it comes to PAYG airtime, the cellular phone then moves against the cultural norm and becomes a transactional instrument as seen in some of the above recorded conversations. This is again borne out in a further example where a student is expressing his delight to the researcher at being accepted into the University:

\section{A: Bonani here. Bandithathile.}

\section{B: Fantastic. Bakuthathile?}

A: Ewe, ngoku kufuneka ndifilishe iifomu zeNSFAS. Andina-air time Prof. Siza kuthetha ngomso.

A: Bonani here. They have taken me.

B: Fantastic. They have taken you?

A: Yes, now I must fill in the NSFAS forms. I don't have air-time, Prof. We will talk tomorrow.

\section{Interviews and conversations: further analysis}

Another interesting facet is that in interviews conducted, all the interviewees point out that they will tend to offer more information and speak longer if they are not paying for the call, thus indicating that the economics of speaking affects all interviewees in a similar way, and that brevity and flouting of cultural and other maxims is dictated by the call initiator and hence the payer. Consequently, in the example above, had the call been initiated by the professor, then the conversation would in all likelihood have been longer and perhaps more in compliance with Grice's maxims. A sample of interview responses to the following question follows: 
Q: Do you speak more when someone phones you, or when you phone someone else?

A: I speak more when someone phones me.

A: When someone phones I speak too much.

A: I don't speak more because I know the way the cellular phone is expensive.

The latter response is unique out of the sample of fifty as it represents the only example of a recipient acknowledging the potential costs being incurred by the initiator. When asked of the impact of cellular communication on the way that you speak, a typical response offered recognition of new words: "In my vocabulary now there are words like call-back, or top-up and even mobile-phone."

Sifianou's (1989) concept of transactional rather than interactional conversation also affects humour in cellular phone conversations. Here the economics of speaking dictates that humour is a luxury rather than a conversational necessity; conversations are generally short and concise. For example, a conversation recorded between same-age young male participants regarding the recent African Cup of Nations Soccer tournament:

A: Anyway, what are the chances of Bafana-Bafana to the AFCON?

$B:$ In reality, I think they could win, but that would be something else though.

A: I really think that if they can play like gangsters then something could happen (laughter). There can be surprises.

B: Unyanisile. But what do you mean when you say playing like-gangsta?

A: Hey, kwedini, uyayazi ukuthi iigangsta zifela emfazweni.

B: I thought about that. Hey, madoda, izinto zakho (laughter). Hey wena, umosha imali yam.

A: Shap' m'fethu.

A: Anyway, what are the chances of Bafana-Bafana to the AFCON (African Cup of Nations)?

B: In reality, I think they could win, but that would be something else though.

A: I really think that if they can play like gangsters then something could happen (laughter). There can be surprises.

B: You are correct. But what do you mean when you say "playing like gangsters"?

A: Hey, boy, you know that gangsters die in wars. 
B: I thought about that. Hey, man, your craziness. (laughter). Hey, you, you are wasting my money.

A: Sharp my friend. (End of Conversation)

In this case the laughter is responsive and it serves to "signal friendly support (solidarity)" (Bowe \& Martin 2007:72). However, it would seem that PAYG cellular phone conversations do not necessarily facilitate laughter as the emphasis is on transactional conversations; hence the maxim of quantity is again flouted. The conversation is ended when interlocutor B indicates that interlocutor A is "wasting my money". Gavioli (1995:375) uses conversational analysis to focus on the use of laughter to mitigate a hearer's frustration or disappointment when negative views are communicated. In the above instance, Bafana Bafana's lack of performance in recent times is couched in humour, in order to indicate both disappointment as well as future possibilities. The conversation is abruptly ended, again emphasising the economics of speaking as being to the detriment of interactional humour filled conversations.

\section{Conclusion}

The use of cellular phones is now a widely recognised phenomenon on the African continent, indeed throughout the world. The expense associated with such conversations has had an effect on rules of conversation and politeness. In other words, conversational rules associated with turn-taking, openings and closings with regard to conversations, as well as humour and Grice's cooperative principle, have all been affected. Nevertheless, cellular phone communication is an imperative conversational tool in modern-day living.

Recognising that the economics of speaking has implications in terms of its impact on culture is essential. The cellular phone has the potential to become an anti-cultural tool in the sense that, insofar as PAYG air-time cellular communication is concerned, the rules that normally pertain to isiXhosa conversations are not necessarily heeded. Openings and closings do not follow normal greeting procedures and politeness rules. Conversations are often only transactional and to the point, they are not interactional as is common with spoken face-toface isiXhosa. Instead, the maxim of quantity as expressed by Grice is what is heeded in such conversations, contrary to cultural expectations. 


\section{Notes}

1. PAYG is defined as not having a contract phone, so the user has to constantly load credit onto their phone in order to make calls.

2. This transference of the maxims offers extensive scope for further research.

\section{References}

Bowe, H. \& Martin, K. 2007. Communication across cultures. Mutual understanding in a global world. Melbourne: Cambridge University Press.

Bloomer, A., P. Griffiths, \& A.J. Merrison. 2005. Introducing language in use. A course book. London and New York: Routledge.

Brown, P. \& S. Levinson. 1978. Universals in language usage: Politeness phenomena. In Goody, E. (ed.) Questions and politeness. Cambridge: Cambridge University Press. pp. 56-324.

Brown, P. \& S. Levinson. 1987. Politeness: Some universals in language usage. Cambridge: Cambridge University Press.

Brown, G. \& G. Yule. 1983. Discourse Analysis. Cambridge: Cambridge University Press.

Clyne, M. 1987. Cultural differences in the organisation of academic discourse. Journal of Pragmatics 11: 211-247.

Clyne, M. 1994. Intercultural communication at work: Cultural values in discourse. Cambridge: Cambridge University Press.

Coulthard, M. 1977. An introduction to discourse analysis. London: Longman Press.

de Kadt, E. 1998. The concept of face and its applicability to the Zulu language. Journal of Pragmatics 29: 173-191.

Dlali, M. 2003. The speech act of complaint in isiXhosa. South African Journal of African Languages 23(3): 131-143.

Dlali, M. 2004. The pragmatics of account giving in political communication in isiXhosa. South African Journal of African Languages 24(1): 1-12.

Gavioli, L. 1995. Turn-initial versus turn-final laughter: Two techniques for initial remedy in English/Italian bookshop service encounters. Discourse Processes 19: 369-384.

Goddard, D. 1977. Same setting, different norms: Phone call beginnings and endings in France and in the United States. Language in Society 6: 209-219.

Goffman, E. 1967. Interaction ritual: Essays on face to face behavior. New York: Doubleday. 
Grice, H.P. 1975. Logic and conversation. In P. Cole \& J. Morgan (eds). Syntax and semantics 3: Speech acts. New York: Academic Press. pp. 41-59.

Kaschula, R.H. 1989. Cross-cultural communication in a north-eastern Cape farming community. South African Journal of African Languages 9(3): 100-104.

Kaschula, R.H. \& Anthonissen, C. 1995. Communicating across cultures in South Africa. Toward a critical language awareness. Johannesburg: Hodder \& Stoughton / Witwatersrand University Press.

Richards , J.C. \& R.W. Schmidt. 1983. Language and communication. London: Longman Publishers.

Sacks, H., E.A. Schegloff \& G. Jefferson, G. 1974. A simplest systematic for the organization of turn-taking in conversation. Language 59: 941-942.

Schegloff, E.A. 1968. Sequencing in conversational openings. In J. Gumperz \& D. Hymes. (eds). Directions in sociolinguistics: The ethnography of communication. New York: Holt, Rinehart \& Winston. pp. 346-80.

Sifianou, M. 1989. On the telephone again! Difference in telephone behaviour: England versus Greece. Language in Society 18: 527-544.

Stubbs, M. 1983. Discourse analysis. The sociolinguistic analysis of natural language. Oxford: Basil Blackwell. 